Z. Klin. Chem. Klin. Biochem.

13. Jg. 1975 , S. $1-12$

\title{
Tryptophan-Stoffwechseluntersuchungen bei unbehandelten Phenylketonurikern
}

\author{
Von W. Kochen, D. J. Byrd, R. Bühner und E. Bührlen \\ Aus der Isotopenabteilung der Universitäts-Kinderklinik (Direktor Prof. Dr. H. Bickel) Heidelberg
}

(Eingegangen am 3. Januar/19. September 1974)

\begin{abstract}
Im Urin von 10 unbehandelten Phenylketonurikern (Alter 4-35 Jahre) wurden die Tryptophan-Metabolite aus dem Kynurenin/Nicotinsäure-Stoffwechselweg quantitativ bestimmt. Alle Patienten sind geistig schwer geschädigt. Die Ergebnisse dieser Untersuchungen führten zu einer Einteilung der Patienten in zwei Gruppen A und B. Bei den Patienten der Gruppe A lag die Ausscheidung von Kynurenin, Kynurensäure, 3-Hydroxykynurenin und Xanthurensäure noch innerhalb der Normgrenze. Nach Tryptophan-Belastung war die Ausscheidung der Metabolite geringer als bei Kontrollen. Von den quantitativ bestimmten Metaboliten wurde im Mittel nur $0,63 \%$ der Belastungsdosis ausgeschieden, im Gegensatz zu 1,13\% bei Kontrollen. In Gruppe B war die Ausscheidung der Metabolite sowohl unter Basal- wie Belastungsbedingungen über die Norm erhöht. Die Ausscheidung nach Tryptophan-Belastung betrug das Vierfache der Norm (4,64 \%). 3-Hydroxyanthranilsäure konnte nur bei der Gruppe B nach Belastung nachgewiesen werden. 8-Hydroxychinaldinsäure, ein anormales Stoffwechselprodukt des Tryptophans, wurde in Milligramm-Mengen ausgeschieden. Die Analyse der Metabolite der 3-Hydroxyanthranilsäure ergab, daß die Ausscheidung von $N_{1}$-Methylnicotinsäureamid und von $N_{1}$-Methyl-2-pyridon-5-carboxamid innerhalb der Norm lag. Nicotinsäure und ihr Amid wurden wie bei der Kontrollgruppe nur sporadisch ausgeschieden. Weitere theoretisch mögliche Metabolite aus diesem Stoffwechselweg konnten nicht nachgewiesen werden.

Zahlreiche unbekannte Metabolite, die entweder nach Tryptophan-Belastung vermehrt ausgeschieden wurden oder überhaupt erst nach Belastung auftraten, konnten dünnschichtchromatographisch nachgewiesen werden. Einige dieser Metabolite wurden nur in Gruppe A oder B beobachtet. Es wird über einen für Gruppe B charakteristischen Metaboliten berichtet, dessen Struktur infolge seiner Instabilität nicht vollständig aufgeklärt werden konnte. Ein stabiles Abspaltungsprodukt wurde massenspektroskopisch als o-Aminoacetophenon identifiziert. Abschließend wird die Beeinflussung des Tryptophan-Stoffwechsels durch den Blutspiegel des Phenylalanins diskutiert.
\end{abstract}

\section{Studies on tryptophan metabolism in untreated phenylketonuric patients}

The products of the oxidative degradation of tryptophan via the kynurenine pathway were quantitatively determined in the urine of ten untreated patients with phenylketonuria, aged 4-35 years. All the patients were severely mentally retarded. The results of the analy sis suggest a division of the patients into two groups, $\mathbf{A}$ and $\mathbf{B}$. The patients of group $\mathbf{A}$ showed a basal urinary excretion of kynurenine, kynurenic acid, 3-hydroxykynurenine and xanthurenic acid which lies in the lower part of the normal range. The increase in excretion of tryptophan metabolites under tryptophan loading was, however, significantly less than in controls. On the average, only $0.63 \%$ of the load was excreted in the form of these assayed metabolites; in contrast, the control value is $1,13 \%$. In group B, the rate of excretion was higher than normal under basal and loading conditions. The post-tryptophan excretion was four times greater than that of controls $(4.64 \%)$. 3-hy.droxyanthranilic acid could only be detected in group B after loading. The metabolite 8-hydroxyquinaldic acid, which is supposed to be an abnormal metabolic product of tryptophan, was excreted in milligram amounts. The analysis of the metabolites of 3-hydroxyanthranilic acid showed that the excretion of $\mathrm{N}_{1}$-methylnicotinamide and $\mathrm{N}_{1}$-methyl-2-pyridone-5-carboxamide was within the normal range. The excretion of nicotinic acid and its amide was sporadic in both the patients and controls. Other theoretically possible metabolites in this pathway could not be found.

A number of unidentified metabolites could be detected by thin-layer chromatography in the basal state. The excretion of these metabolites was greatly augmented after tryptophan loading. Other substances which were not detectable in the basal state became evident on loading. A number of these metabolites are characteristic either of group A or B. The structural identification of one of the new products has been hindered by its instability. A stable cleavage product was identified as $\sigma$-aminoacetophenon by mass-spectroscopy. This metabolite is typical for group $B$.

The possible influence of the blood phenylalanine on the metabolism of tryptophan in phenylketonuria is discussed.

Die Phenylketonurie gehört zu denjenigen angeborenen Stoffwechselerkrankungen, die hinsichtlich des Primärdefektes biochemisch grïndlich untersucht worden sind. Dennoch ist die Ursache der Hirnschädigung nicht befriedigend abgeklärt; es gibt Patienten mit biochemisch diagnostizierter Phenyiketonurie, die ohne diätetische Behandlung keine Beeinträchtigung der Intelligenz und keine oder nur geringe neurologische Schäden zeigen (1-5). Es besteht die Möglichkeit, daß der biochemische Primärbefund eines gestörten Phenylalanin-Abbaus nicht oder nicht allein als Ursache für die Hirnschädigung anzusehen ist, sondern sekundäre Stoffwechselstörungen verantwortlich gemacht werden müssen. Dazu könnte die von Armstrong \& Robinson (6) 1954 zum ersten 
Male beobachtete Störung im Tryptophan-Stoffwechsel gehören, die durch eine erhöhte Ausscheidung von Indolsäuren gekennzeichnet ist. Quantitative Abweichungen von der Norm wurden aber auch bei den Stoffwechselprodukten aus dem oxydativen Abbau des Tryptophans beobachtet (7-11).

Um einen detaillierten Einblick in den Tryptophan-Stoffwechsel bei Phenylketonurie zu bekommen, wurde zunächst mit einer verbesserten analytischen Methode (12) die Ausscheidung der indolischen Metabolite bestimmt (13). In der vorliegenden Arbeit werden bei denselben Phenylketonurie-Patienten auch die Tryptophan-Metabolite aus der Reihe Kynurenin/3-Hydroxyanthranilsäure/Nicotin-Adenindinucleotid (NAD) untersucht. Die bisher veröffentlichten Ergebnisse über die Ausscheidung dieser Metabolite bei der Phenylketonürie sind nicht einheitlich (7-11). Die angewandten methodischen Verfahren entsprechen nicht mehr modernen analytischen Anforderungen. Eine weitere Erschwerung bei der Beurteilung der Literaturergebrisse entsteht dadurch, daß es atypische Formen der Phenylketonurie gibt, die klinisch und biochemisch von der zuerst durch Fölling beschriebenen ,klassischen“ Phenylketonürie abgegrenzt werden müssen. Phenylalanin-Werte über $200 \mathrm{mg} / \mathrm{l} \mathrm{Serum}$ sind für die klassiche Phenylketonurie charakteristisch. Bei Werten unter $200 \mathrm{mg} / \mathrm{I}$ wird die Hyperphenylalaninämie abgegrenzt, wobei jedoch mehrere Unterteilungen erforderlich werden (14). Die Möglichkeit neuer, von der klassischen Phenylketonurie abweichender molekulargenetischer Defekte ist durchaus in Betracht zu ziehen (15).

\section{Methodik und Material}

\section{Methoden}

Der Sammelurin wird tiefgefroren bis zur Aufarbeitung aufbewahrt. Die Auftrennung der Tryptophan-Metabolite Kynurenin, 3-Hydroxykynurenin, Kynuren- und Xanthurensäure, Anthranilsäure und 3-Hydroxyanthranilsäure erfolgt säulenchromatographisch auf dem stark sauren Kationenaustauscher Amberlite IR-120/AS. Eluiert wird mit zwei flüchtigen, wäßrigen Ameisensäure/Pyridin-Gemischen vom pH 2,60 und 5,60. Die gefriergetrockneten Fraktionen werden dünnschichtchromatographisch (Cellulose mit Fluoreszenzindikator) untersucht. Laufmittel: $n$-Butanol/Eisessig/Wasser $(40 \mathrm{ml}+10 \mathrm{ml}+50 \mathrm{ml})$. Nach einer 2. Chromatographie auf Fertigplatten (Cellulose und/oder Polyamid, Firma Merck, Darmstadt) erfolgt die quantitative Auswertung in situ mit Hilfe des Dünnschicht-Fluorometers nach Tumer (Firma Camag, Muttenz) und/oder nach Anfärbung und Auswertung mit dem Dünnschicht-Spektralphotometer von Zeiss. Einzelheiten über den Trennungsgang siehe 1.c. (16).

Zur Analyse der Nicotinsäure-Derivate, der Chinaldin- und 8Hydroxychinaldinsäure wird der Trockenrückstand eines.Teils des 24-h-Urins $(10 \mathrm{ml})$ mit ammoniakalischem Äthanol extrahiert, anschließend erfolgt eine Säulenchromatographie auf SP-Sephadex und Entwicklung mit Äthanol/Wasser $(90 \mathrm{ml}$ $+10 \mathrm{ml}$ ). Die Fraktionen werden dünnschichtchromatographisch untersucht, indem die Kieselgel-Platte in drei aufeinander folgenden basischen Laufmittelsystemen entwickelt wird. Die Metabolite werden in situ quantitativ ausgewertet, indem ihre Absorption im ultravioletten bzw. nach Anfärbung die Absorption im sichtbaren Bereich gemessen wird. Ebenso wird die Fluoreszenzstrahlung zur quantitativen Messung ausgenutzt. Aliquote der Säulenfraktionen werden nach Veresterung mit
Diazomethan für die gaschromatographische Analyse verwendet. $\mathrm{N}_{\mathrm{i}}$-Methylnicotinsäureamid wird in einer gesonderten Urinprobe bestimmt: Extraktion des Urin-Trockenrüickstandes mit Methanol/Wasser $(90 \mathrm{ml}+10 \mathrm{ml})$, Säulenchromatographie auf DEAE- oder QAE- Sephadex mit Äthanol/Wasser $90 \mathrm{ml}+10 \mathrm{ml}$ ), anschließend Dünnschichtchromatographie und quantitative Bestimmung direkt auf der Platte. Die Methode zur Bestimmung der Nicotinsäurederivate und der Chinaldinsäuren wird ausführlich von Byrd \& Kochen (17) beschrieben.

\section{Probanden}

Für die Untersuchung des Tryptophan-Stoff'wechsels bei der Phenylketonurie wurden zehn Patienten aus den Johannes-Anstalten in Mosbach ausgewählt. In Reihenuntersuchungen mit dem Guthrie-Test zur Bestimmung des Phenylalanins im Blut waren diese Patienten als Phenylketonuriker erkannt worden. Bei drei Kindern aus diesem Kollektiv (Nr, 1-3) war die Diagnose bekannt. Sie waren dietätisch ohne Erfolg behandelt worden. Die Krankengeschichten, vor allem die der älteren Patienten, sind sehr unvollkommen. Alle Patienten sind geistig schwer geschädigt, ihr Schwachsinnsgrad wird als imbezill und idiotisch angegeben (Tab. 1).

Bei den Patienten Nr. 1-7 wurde eine höhere P.henylalaninKonzentration im Blut festgestellt als bei den Patienten Nr. 8-10. Dies wird bei der Interpretation der Ergebnisse von Bedeutung sein.

Eine Woche vor dem Urinsammeln wurden jegliche Medikamente abgesetzt. Die Ernährung war frei und entsprach der normalen Anstaltskost.

\section{Ergebnisse}

Die Analyse der oxydativen Abbauprodukte des Tryptophans im Urin der 10 Patienten führte nicht zu einheitlichen Ergebnissen. Es konnte kein für alle Pätienten guiltiges qualitatives und quantitatives Ausscheidungsmuster festgestellt werden. Tabelle 2 zeigt, daß alle Patienten Kynurenin, Kynurensäure und Xanthurensäure ausscheiden, während dies für 3-Hydroxykynurenin und 3-Hydroxyanthranilsäure nicht zutrifft. Anthranilsäure konnte bei keinem Patienten nachgewiesen werden. Dieser Metabolit ist bei Kontrollversuchen nur nach Tryptophan-Belastung nachweisbar. Die quantitativen Ergebnisse, besonders die nach Tryptophan-Belastung, zeigen auffallende Unterschiede. Aber auch die Basalwerte weichen bei mehreren Metaboliten erheblich von der Norm ab. Es gibt Patienten, die nach TryptophanBelastung durch eine exzessive Ausscheidung von bestimmten Metaboliten charakterisiert sind. Dies wird besonders deutlich bei Kynurensäure, 3-Hydroxykynurenin und 3-Hydroxyan thranilsäure. Durch Vergleich der quantitativen Daten der einzelnen Patienten untereinander und zu den Kontrollen ergab sich eine Einteilung der Patienten in 2 Gruppen A und B. Die Ergebnisse aus beiden Gruppen sind in Tabelle 2 zusammengefaßt. Folgende Aussagen können für die Basalausscheidung bei Gruppe A gemacht werden:"

\section{Gruppe A}

1. Die Mittelwerte der Basalausscheidung von Kynurenin und Xanthurensäure liegen im Normbereich; Kynurensäure überschreitet geringfügig die obere Normgrenze. Bei Patient Nr. 7 ist Kynurenin, bei Patient Nr. 6 und 7 Kynurensäure erhöht. 
Tab. 1. Ubersicht über die 10 Patienten mit unbehandelter Phenylketonurie.

\begin{tabular}{|c|c|c|c|c|c|c|c|}
\hline \multirow{2}{*}{$\begin{array}{l}\text { Patient, } \\
\text { Geschlecht, } \\
\text { Geburtsdatum }\end{array}$} & \multicolumn{2}{|c|}{ Phenylalanin mg/l } & \multirow[t]{2}{*}{ Geschwister } & \multirow{2}{*}{$\begin{array}{l}\text { Intelligenzquo- } \\
\text { tient Bühler- } \\
\text { Hetzer-Test }\end{array}$} & \multirow{2}{*}{$\begin{array}{l}\text { Diagnose } \\
\text { gestellt }\end{array}$} & \multirow[t]{2}{*}{ Therapie } & \multirow[t]{2}{*}{ Symptomatik } \\
\hline & $\begin{array}{l}\text { Guthrie-Test } \\
\text { (Vollblut) }\end{array}$ & $\begin{array}{l}\text { Säulenchromato- } \\
\text { graphie (Serum) }\end{array}$ & & & & & \\
\hline $\begin{array}{l}1 \mathrm{Ke.} \mathrm{J.,} \delta \\
\text { 2.11. } 66\end{array}$ & 1969: $>200$ & 154 & 1 gesund & 0,54 & 1969 & $\begin{array}{l}\text { Diät } \\
\text { ohnc Erfolg }\end{array}$ & \\
\hline $\begin{array}{l}2 \text { Ro. D., o } \\
\text { 8. } 7.65\end{array}$ & $\begin{array}{l}\text { 1966: }>200 \\
\text { 1968: } 60-120 \\
1970 / 71:>200\end{array}$ & $150-180$ & gesund & 0,34 & 1966 & $\begin{array}{l}\text { Diät } \\
\text { ohne Erfolg }\end{array}$ & $\begin{array}{l}\text { Blitz-Nick- } \\
\text { Solaam- } \\
\text { Krämpfe }\end{array}$ \\
\hline $\begin{array}{l}3 \text { We. N., ? } \\
\text { 11. 10. } 61\end{array}$ & $\begin{array}{l}1968: 120-200 \\
1969 / 70:>200\end{array}$ & $180-200$ & $\begin{array}{l}2 \text { \& Phenyl- } \\
\text { ketonurie } \\
2 \text { o gesund }\end{array}$ & 0,25 & 1962 & $\begin{array}{l}\text { Diät } \\
\text { ohne Erfolg }\end{array}$ & Krämpfe \\
\hline $\begin{array}{l}4 \mathrm{Ga} . \mathrm{F} ., \delta \\
\text { 13. } 12.56\end{array}$ & 1969: > 200 & 250 & - & 0,30 & 1969 & keine & $\begin{array}{l}\text { motorische } \\
\text { Unruhe, } \\
\text { Schreiattacken }\end{array}$ \\
\hline $\begin{array}{l}5 \text { He. M., } 8 \text {, } \\
\text { 13. } 9.56\end{array}$ & 1969: > 200 & 260 & gesund & 0,30 & 1969 & keine & \\
\hline $\begin{array}{l}6 \text { Cz. B., } \delta, \\
12.8 .52\end{array}$ & $\begin{array}{l}\text { 1969: } 120 \\
\text { 1970: } 200\end{array}$ & $\begin{array}{l}100-160 \\
100-160\end{array}$ & gesund & 0,20 & 1969 & keine & $\begin{array}{l}\text { motorische } \\
\text { Unruhe, } \\
\text { Schreiattacken }\end{array}$ \\
\hline $\begin{array}{l}7 \text { Hi. E., } \delta, \\
\text { 30. 12. } 51\end{array}$ & 1969: > 200 & & $\begin{array}{l}\text { Zwillingsbrüder } \\
\text { Phenylketonurie }\end{array}$ & $e^{0,25}$ & 1969 & keine & $\begin{array}{l}\text { ausgeprägte } \\
\text { Degenerations- } \\
\text { zeichen }\end{array}$ \\
\hline $\begin{array}{l}8 \text { Wa. M., } \delta, \\
\text { 22. 10. } 35\end{array}$ & $\begin{array}{l}\text { 1968: } 120-200 \\
\text { 1969: } 80-120\end{array}$ & 68 & $\begin{array}{l}3 \text { (Hilfsschule) } \\
2 \text { gesund }\end{array}$ & 0,65 & 1968 & keine & \\
\hline $\begin{array}{l}9 \text { Li. U., ?, } \\
\text { 1. 10. } 50\end{array}$ & $\begin{array}{l}\text { 1968: } 120-200 \\
\text { 1969: } 80-120 \\
\text { 1970: } 150-200\end{array}$ & $80-120$ & 1 gesund & & $1968,+1971$ & keine & $\begin{array}{l}\text { schwere gei- } \\
\text { stige Retar- } \\
\text { dation }\end{array}$ \\
\hline $\begin{array}{l}10 \text { Mu. J., ?, } \\
\text { 18. } 9.47\end{array}$ & $\begin{array}{l}1968: 120-200 \\
1969: 120-200\end{array}$ & $\begin{array}{l}65 \\
60-80\end{array}$ & $\begin{array}{l}1 \text { Phenylketon- } \\
\text { urie } \\
1+\text { Phenyl- } \\
\text { ketonurie(?) }\end{array}$ & & 1968 & keine & $\begin{array}{l}\text { schwere gei- } \\
\text { stige Retar- } \\
\text { dation }\end{array}$ \\
\hline
\end{tabular}

2. Abweichend von der Norm erfolgt keine Ausscheidung von 3-Hydroxyanthranilsäure.

3. 3-Hydroxykynurenin wird bei funf der sieben $\mathrm{Pa}$ tienten nicht oder nur in Spuren ausgeschieden. Patient Nr. 6 zeigt eine vermehrte Ausscheidung.

Nach Belastung mit $0,1 \mathrm{~g} L$-Tryptophan/kg Körpergewicht zeigt sich, daß die Summe der quantitativ bestimmten Metabolite in Gruppe $A$ in den ersten $24 \mathrm{~h}$ im Mittel nur 0,65\% der verabreichten oralen Dosis beträgt. Dieser Wert ist im Vergleich zum mittleren Kontrollwert, der $1,13 \%$ beträgt, vermindert. Die mittlere Ausscheidung von Kynurenin ist herabgesetzt. Bei den Patienten Nr. 6 und 7 liegt die Belastungsausscheidung jedoch innerhalb der Normgrenze. Patient Nr. 1 zeigt nach Belastung sogar eine deutlich geringere Ausscheidung des Kynurenins als im Basalurin; bei Patient Nr. 2 ist die Erhöhung nur geringfügig. Bei einer Wiederholung der Tryptophan-Belastung bei diesen beiden Patienten konnte.der Befund reproduziert werden. Es ist bemerkenswert, daß 3-Hydroxyanthranilsäure nur bei Patient Nr. 6 nach Belastung ausgeschieden wird.

\section{Gruppe B}

Die 3 Patienten der Gruppe B scheiden von dem verabreichten Tryptophan einen wesentlich größeren Anteil in Form der identifizierten Metabolite aus: $4,64 \%$ der Dosis gegenüber nur 0,65\% bei der Gruppe A. Diese
Ausscheidungsquote von $4,64 \%$ beträgt mehr als das Vierfache der Norm. Charakteristische Unterscheidungsmerkmale zur Gruppe A sind:

1. Die Basalwerte liegen ohne Ausnahme höher als in Gruppe A. Der Unterschied ist weniger deutlich bei Kynurenin als bei 3-Hydroxykynurenin und Xanthurensäure.

2. Nach Tryptophan-Belastung tritt eine signifikante Steigerung der Ausscheidung ein, die die Norm um ein Vielfaches übersteigt.

3. 3-Hydroxyanthranilsäure wird erst nach Belastung in einer Menge ausgeschieden, die im Mittel die obere Normgrenze überschreitet.

Patient Nr. 9 fällt durch extrem hohe Ausscheidungsraten auf, wie wir sie bisher noch in keinem Falle beob: achten konnten. Die in Tabelle 2 aufgefuhrten Belastungswerte beziehen sich auf eine 10-h-Urinportion. Eine Wiederholung des Belastungsversuches mit 5,0 $\mathrm{g} L$-Tryptophan, wobei ein 24-h-Urin exakt gesammelt werden konnte, wurde aber durch einen fiebrigen Infekt gestört. Die Werte pro $24 \mathrm{~h}$ betrugen: Kynurenin $191 \mathrm{mg}$, Kynurensäure $150 \mathrm{mg}$, 3-Hydroxykynurenin $220 \mathrm{mg}$, Xanthurensäure $53 \mathrm{mg}$ und 3-Hydroxyanthranilsäure $19,7 \mathrm{mg}$. Insgesamt wurden $12,55 \%$ der TryptophanDosis in den ersten $24 \mathrm{~h}$ in Form dieser Metabolite wieder ausgeschieden. 
Tab. 2. Ausscheidung von Tryptophan-Metaboliten aus dem Kynurenin-Abbau im Urin von unbehandelten Phenylketonurikern (mg/24-h-Urin) im Basalurin und 24-h-Urin nach oraler Belastung mit 0,1 g/kg $L$-Tryptophan.

* Belastung mit $0,05 \mathrm{~g} / \mathrm{kg} \mathrm{L}$-Tryptophan

** 10-h-Urin nach Tryptophan-Belastung.

\begin{tabular}{|c|c|c|c|c|c|c|c|c|c|c|c|c|c|}
\hline \multirow[t]{3}{*}{$\begin{array}{l}\text { Patient, Körpergewicht, } \\
\text { Alter }\end{array}$} & \multicolumn{2}{|c|}{ Kynurenin } & \multicolumn{2}{|c|}{$\begin{array}{l}\text { Kynuren- } \\
\text { säure }\end{array}$} & \multicolumn{2}{|c|}{$\begin{array}{l}\text { 3-Hydroxy- } \\
\text { kynurenin }\end{array}$} & \multicolumn{2}{|c|}{$\begin{array}{l}\text { Xanthuren- } \\
\text { säure }\end{array}$} & \multicolumn{2}{|c|}{$\begin{array}{l}\text { 3-Hydroxy- } \\
\text { anthranil- } \\
\text { säure }\end{array}$} & \multicolumn{2}{|c|}{$\begin{array}{l}\text { Anthranil- } \\
\text { säure }\end{array}$} & \multirow[t]{3}{*}{$\begin{array}{l}\text { \% der Trypto- } \\
\text { phan-Dosis } \\
(0,1 \mathrm{~g} / \mathrm{kg} \mathrm{KG})\end{array}$} \\
\hline & vor & nach & vor & nach & vor & nach & vor & nach & vor & nach & vor & nach & \\
\hline & \multicolumn{2}{|c|}{$\begin{array}{l}\text { Tryptophan- } \\
\text { belastung }\end{array}$} & \multicolumn{2}{|c|}{$\begin{array}{l}\text { Tryptophan- } \\
\text { belastung }\end{array}$} & \multicolumn{2}{|c|}{$\begin{array}{l}\text { Tryptophan- } \\
\text { belastung }\end{array}$} & \multicolumn{2}{|c|}{$\begin{array}{l}\text { Tryptophan- } \\
\text { belastung }\end{array}$} & \multicolumn{2}{|c|}{$\begin{array}{l}\text { Tryptophan- } \\
\text { belastung }\end{array}$} & \multicolumn{2}{|c|}{$\begin{array}{l}\text { Tryptophan- } \\
\text { belastung }\end{array}$} & \\
\hline $\begin{array}{l}\text { Gruppe A } \\
1 \text { Ke. J., } 13 \mathrm{~kg}, 4 \mathrm{~J} . \\
2 \text { Ro. D., } 15 \mathrm{~kg}, 5 \mathrm{~J} . \\
3 \text { We. N., } 22 \mathrm{~kg}, 9 \mathrm{~J} . \\
4 \text { Ga. F., } 29 \mathrm{~kg}, 14 \mathrm{~J} . \\
5 \mathrm{He} \text {. M., } 38 \mathrm{~kg}, 14 \mathrm{~J} . \\
6 \mathrm{Cz} . \text { B., } 58 \mathrm{~kg}, 18 \mathrm{~J} . \\
7 \text { Hi. E., } 58 \mathrm{~kg}, 19 \mathrm{~J} .\end{array}$ & $\begin{array}{l}1,30 \\
0,69 \\
0 \\
0,58 \\
1,42 \\
0,86 \\
3,27\end{array}$ & $\begin{array}{c}0,51 \\
0,91 \\
1,32 \\
4,44 \\
3,15 \\
17,78 \\
10,06 *\end{array}$ & $\begin{array}{c}0,68 \\
0 \\
1,61 \\
2,59 \\
1,27 \\
6,03 \\
4,45\end{array}$ & $\begin{array}{r}4,16 \\
3,50 \\
3,09 \\
10,69 \\
14,09 \\
17,52 \\
11,54\end{array}$ & $\begin{array}{c}+ \\
+ \\
0 \\
+ \\
0 \\
3,36 \\
0,91\end{array}$ & $\begin{array}{c}0,66 \\
0,10 \\
+ \\
5,11 \\
0 \\
5,12 \\
3,66\end{array}$ & $\begin{array}{c}0,63 \\
0 \\
1,14 \\
0,32 \\
0,33 \\
1,13 \\
0,41\end{array}$ & $\begin{array}{r}1,86 \\
0,65 \\
3,58 \\
6,03 \\
1,47 \\
15,05 \\
3,52\end{array}$ & $\begin{array}{l}0 \\
0 \\
0 \\
0 \\
0 \\
0 \\
0\end{array}$ & $\begin{array}{l}0 \\
0 \\
0 \\
0 \\
0 \\
2,7 \\
0\end{array}$ & $\begin{array}{l}0 \\
0 \\
0 \\
0 \\
0 \\
0 \\
0\end{array}$ & $\begin{array}{l}0 \\
0 \\
0 \\
0 \\
0 \\
0 \\
0\end{array}$ & $\begin{array}{l}0,53 \\
0,50 \\
0,41 \\
0,89 \\
0,23 \\
1,03 \\
0.97\end{array}$ \\
\hline$\overline{\mathbf{x}}$ & 1,16 & 5,45 & 2,37 & 7,80 & 0,61 & 2,09 & 0,56 & 4,60 & 0 & 0,38 & 0 & 0 & 0,65 \\
\hline $\begin{array}{l}\text { Gruppe B } \\
8 \text { Wa. M., } 53 \mathrm{~kg}, 35 \mathrm{~J} . \\
9 \mathrm{Li} . \mathrm{U} ., 78 \mathrm{~kg}, 20 \mathrm{~J} . \\
10 \mathrm{Mu} . \mathrm{J} ., 65 \mathrm{~kg}, 23 \mathrm{~J} .\end{array}$ & $\begin{array}{l}1,00 \\
2,66 \\
1,66\end{array}$ & $\begin{array}{c}56,68 \\
149,05 * * \\
91,70\end{array}$ & $\begin{array}{r}5,70 \\
* 6,50 \\
6,94\end{array}$ & $\begin{array}{r}41,93 \\
109,25 \\
87,00\end{array}$ & $\begin{array}{c}4,00 \\
0 \\
7,20\end{array}$ & $\begin{array}{r}85,42 \\
134,01 \\
58,80\end{array}$ & $\begin{array}{l}2,82 \\
3,88 \\
1,35\end{array}$ & $\begin{array}{l}29,05 \\
46,15 \\
27,16\end{array}$ & $\begin{array}{l}0 \\
0 \\
0\end{array}$ & $\begin{array}{r}6,78 \\
11,90 \\
2,33\end{array}$ & $\begin{array}{l}0 \\
0 \\
0\end{array}$ & $\begin{array}{l}0 \\
0 \\
0\end{array}$ & $\begin{array}{l}4,09 \\
5,71 \\
4,12\end{array}$ \\
\hline$: \overline{\mathbf{x}}$ & 1,77 & 99,14 & 6,38 & 79,39 & 3,73 & 92,74 & 2,68 & 34,12 & 0 & 7,00 & 0 & 0 & 4,64 \\
\hline $\begin{array}{l}\text { Kontrollpers. (16) } \\
\text { Neuere Normalwerte } \\
(\mathrm{N}=6)\end{array}$ & $\begin{array}{l}0,87 \\
1,35 \\
\pm 0,4\end{array}$ & $\begin{array}{l}- \\
15,0 \\
\pm 6,0\end{array}$ & $\begin{array}{r}1,00 \\
1,78 \\
\pm 6,0\end{array}$ & $\begin{array}{r}- \\
16,0 \\
\pm 10,0\end{array}$ & $\begin{array}{r}0,89 \\
0,95 \\
\pm 0,3\end{array}$ & $\begin{array}{r}-\overline{6,8} \\
\pm 4,5\end{array}$ & $\begin{array}{r}0,59 \\
0,95 \\
\pm 0,4\end{array}$ & $\begin{array}{l}\overline{12,0} \\
\pm 8,0\end{array}$ & $\begin{aligned} 0,58 \\
0,60 \\
\pm 0,3\end{aligned}$ & $\begin{array}{r}4 \overline{5} \\
\pm 1,5\end{array}$ & $\begin{array}{l}0 \\
0 \\
0\end{array}$ & $\overline{\max }_{1,0}$ & $\begin{array}{l}1,13 \\
(0,95-1,75)\end{array}$ \\
\hline
\end{tabular}

\section{Ausscheidungsquotienten}

Die Unterschiede zwischen Gruppe A und B werden noch deutlicher, wenn man den Quotienten aus Belastungs- und Basalwert bildet. Die Mittelwerte dieser Quotienten sind in Tabelle 3 angegeben, aus der man ersehen kann, daß der Erhöhungsfaktor der Gruppe B gegenüber Gruppe A bei Kynurenin 11,9, bei Kynurensäure 3,7, bei 3-Hydroxykynurenin 7,3 und bei Xanthurensäure 1,5 beträgt. Die bei Kontrolluntersuchungen ermittelten Quotienten weichen erheblich von den errechneten Werten aus der Literatur ab, was unserer Meinung nach auf methodische Gründe zurückzuführen ist.

\section{Nachweis von Säuren des Chinolins}

Auf der Suche nach weiteren oxydativen Abbauprodukten konnten in größeren Mengen zwei Säuren des Chinolins, die Chinaldinsäure und ihr 8-Hydroxyderivat, nachgewiesen werden. Die Chinaldinsäure wird nicht von allen Kontrollpersonen ausgeschieden (17). Ist der Metabolit im Basalurin nicht nachweisbar, so kann auch nach Belastung mit $L$-Tryptophan keine Ausscheidung festgestellt werden. Diese für Kontrollen gültige Aussage konnte jedoch bei Patient Nr. 8 nicht bestätigt werden. Die bei den vier untersuchten Phenylketonurie -Patienten ermittelten Basalwerte der Chinaldinsäure sind vermindert. Patient Nr. 9 fällt durch eine extrem hohe Ausscheidung der Chinaldinșäure nach Belastung auf (Tab. 4).

8-Hydroxychinaldinsäure ist ein Tryptophan-Metabolit, der bisher in Kontrolluntersuchungen nicht nachgewiesen werden konnte. Seine Ausscheidung muß als anormal bezeichnet werden (18). Der Nachweis dieses Metaboliten bei 3 von 4 untersuchten Fällen ist besonders bemerkenswert. Nach Belastung kann eine vermehrte Ausscheidung nicht festgestellt werden. Eine Ausnahme stellt wiederum Patientin Nr. 9 dar. (Diese Patientin verstarb kurze Zeit nach diesen Untersuchungen im Verlauf eines hochfiebrigen Infektes an Herz-Kreislauf-Versagen).

Bei diesem Patienten wurde nach Beobachtungen des Pflegepersonals periodenweise eine starke Unruhe und Erregbarkeit, teilweise bis zu Schreiattacken und Krämpfen, festgestellt. Da ein möglicher Zusammenhang zwischen der Ausscheidung der 8-Hydroxychinaldinsäure und Vitamin $\mathrm{B}_{6}$-abhängigen Krämpfen besteht (18), sahen wir uns zu der Prüfung veranlaßt, ob die Aus: scheidung dieses Metaboliten auch in einem Zusammenhang zu der Verhaltensweise der Phenylketonurie-Patienten stehen könnte. Es wurden daher bei 2 Patienten Urinproben aus Perioden mit unterschiedlicher Verhaltensweise gesammelt. Wie Tabelle 5 zeigt, kann an sog. „unruhigen" Tagen mit Schreiattacken und äußerster 
Tab. 3. Verhältnis Mittelwert der Ausscheidung nach Tryptophan-Belastung zu Mittelwert Basalausscheidung.* Eigene Ergebnisse bei Kontrollpersonen.** Kynurenin + Acetyl-Kynurenin,*** + Anthranilsäure-Glucuronid.

\begin{tabular}{|c|c|c|c|c|c|c|}
\hline & Kynurenin & Kynurensäure & $\begin{array}{l}\text { 3-Hydroxy- } \\
\text { kynurenin }\end{array}$ & $\begin{array}{l}\text { Xanthuren- } \\
\text { säure }\end{array}$ & $\begin{array}{l}\text { 3-Hydroxy- } \\
\text { anthranilsäure }\end{array}$ & Anthranilsäure \\
\hline $\begin{array}{l}\text { Phenylketonurie Gruppe A } \\
\text { Phenylketonurie Gruppe B }\end{array}$ & $\begin{array}{r}4,7 \\
56,0\end{array}$ & $\begin{array}{r}3,3 \\
12,4\end{array}$ & $\begin{array}{r}3,4 \\
24,9\end{array}$ & $\begin{array}{r}8,2 \\
12,7\end{array}$ & $\begin{array}{l}\text { bis } 0,4 \mathrm{mg} \\
\text { bis } 7,0 \mathrm{mg}\end{array}$ & $\begin{array}{l}0 \\
0\end{array}$ \\
\hline $\begin{array}{l}\text { Kontrollpersonen* } \\
0,1 \mathrm{~g} / \mathrm{kg} L \text {-Tryptophan }\end{array}$ & 11,1 & 9,0 & 7,1 & 12,6 & 7,5 & $\begin{array}{l}\text { bis } 1 \mathrm{mg} \text { nach } \mathrm{Be}- \\
\text { lastung }\end{array}$ \\
\hline $\begin{array}{l}\text { Literaturvergleich } \\
\text { Kontrollpersonen ( } 58) \\
0,1 \mathrm{~g} / \mathrm{kg} \mathrm{L} \text {-Tryptophan }\end{array}$ & & & & & & \\
\hline $\begin{array}{l}\text { Kinder } \\
\text { Männer } \\
\text { Frauen }\end{array}$ & $\begin{array}{l}17,5 * * \\
29,3 * * \\
80,9 * *\end{array}$ & $\begin{array}{l}12,2 \\
14,3 \\
34,4\end{array}$ & $\begin{array}{r}3,8 \\
6,0 \\
12,2\end{array}$ & $\begin{array}{r}4,5 \\
7,0 \\
30,9\end{array}$ & $\begin{array}{l}3,1 \\
4,9 \\
7,1\end{array}$ & $\begin{array}{r}5,9 * * * \\
10,0 * * * \\
13,6 * * *\end{array}$ \\
\hline $\begin{array}{l}\text { Kontrollpersonen (59) } \\
\text { Erwachsene, } 1 \text { g } L \text {-Tryptophan } \\
\text { Kinder, } 6 \mathrm{~J} ., 1 \text {, } 5 \text {-Tryptophan } \\
\text { Kinder, } 13 \text { J., 2,0 g } L \text {-Tryptophan }\end{array}$ & $\begin{array}{r}26,5 \\
3,1 \\
2,8\end{array}$ & $\begin{array}{l}4,6 \\
3,7 \\
2,9\end{array}$ & $\begin{array}{l}2,9 \\
1,4 \\
2,0\end{array}$ & $\begin{array}{l}5,0 \\
3,8 \\
3,2\end{array}$ & $\begin{array}{l}- \\
-\end{array}$ & $\begin{array}{l}- \\
-\end{array}$ \\
\hline $\begin{array}{l}\text { Kontrollpersonen (8) } \\
\text { Kinder } \\
0,1 \mathrm{~g} / \mathrm{kg} L \text {-Tryptophan, max. } \\
2,0 \mathrm{~g} / \mathrm{kg} L \text {-Tryptophan }\end{array}$ & 2,8 & 7,3 & 1,6 & 2,8 & - & $\begin{array}{l}\text { basal: } 0-0,017 \mathrm{mg} / \mathrm{kg} \\
\text { nach Belastung: } \\
0-0,039 \mathrm{mg} / \mathrm{kg}\end{array}$ \\
\hline
\end{tabular}

Tab. 4. Ausscheidung von Tryptophan-Metaboliten aus dem Nicotinsäure-Stoffwechselweg und von 2 Chinolinderivaten (mg/24-hUrin).

\begin{tabular}{|c|c|c|c|c|c|c|c|c|c|c|}
\hline \multirow{4}{*}{$\frac{\text { Metabolit }}{\text { Chinaldinsäure }}$} & \multirow{3}{*}{\multicolumn{2}{|c|}{$\begin{array}{l}\text { Pat. } 7 \\
\text { vor nach } \\
\text { Tryptophan- } \\
\text { belastung }\end{array}$}} & \multicolumn{2}{|c|}{ Pat. 8} & \multicolumn{2}{|l|}{ Pat. 9} & \multicolumn{2}{|c|}{ Pat. 10} & \multicolumn{2}{|c|}{ Kontrollpersonen $(\mathrm{N}=8)$} \\
\hline & & & vor & nach & vor & nach. & vor & nach & vor & nach \\
\hline & & & \multicolumn{2}{|c|}{$\begin{array}{l}\text { Tryptophan- } \\
\text { belastung }\end{array}$} & \multicolumn{2}{|c|}{$\begin{array}{l}\text { Tryptophan- } \\
\text { belastung }\end{array}$} & \multicolumn{2}{|c|}{$\begin{array}{l}\text { Tryptophan- } \\
\text { belastung }\end{array}$} & \multicolumn{2}{|c|}{ Tryptophanbelastung } \\
\hline & 4,1 & 30,2 & 0 & $16 ; 5$ & 7,7 & 170,0 & 10,4 & 90,5 & $\begin{array}{l}35,85 \\
(11 ; 2-77,6)\end{array}$ & $\begin{array}{l}67,24 \\
(11,7-149,4)\end{array}$ \\
\hline $\begin{array}{l}\text { 8-Hydroxychinaldinsäure } \\
\text { Chinolinsäure } \\
\text { Nicotinsäure } \\
\text { Nicotinsäureamid } \\
\text { N}_{1} \text {-Methylnicotinsäureamid }\end{array}$ & $\begin{array}{c}2,0 \\
0 \\
0 \\
0 \\
4,50\end{array}$ & $\begin{array}{l}3,0 \\
0 \\
0 \\
+ \\
7,90\end{array}$ & $\begin{array}{c}8,6 \\
0 \\
0 \\
0 \\
7,80\end{array}$ & $\begin{array}{l}7,5 \\
0 \\
0 \\
0 \\
10,30\end{array}$ & $\begin{array}{l}2,8 \\
0 \\
3,66 \\
3,42 \\
4,20\end{array}$ & $\begin{array}{l}13,8 \\
0 \\
0 \\
0,97 \\
10,40\end{array}$ & $\begin{array}{c}0 \\
0 \\
0 \\
20,70 \\
2,14\end{array}$ & $\begin{array}{c}0 \\
0 \\
0 \\
11,60 \\
3,55\end{array}$ & $\begin{array}{l}0 \\
0 \\
0-3,5 \\
0-1,4 \\
\text { I } 53,62 \\
\text { II } 5,45\end{array}$ & $\begin{array}{l}0 \\
0 \\
0-4,4 \\
0-2,7 \\
30,90 \mathrm{~N}=4 \\
12,88 \mathrm{~N}=4\end{array}$ \\
\hline $\begin{array}{l}\text { Nicotinursäure } \\
\text { Nicotinsäureamid-N-Oxid } \\
\mathrm{N}_{1} \text {-Methyl-2-pyridon- } \\
\text { 5-carboxamid } \\
\mathrm{N}_{1} \text {-Methyl-4-pyridon- } \\
\text { 5-carboxamid }\end{array}$ & $\begin{array}{l}0 \\
+(?) \\
6,80 \\
+(?)\end{array}$ & $\begin{array}{l}0 \\
+(?) \\
9,21 \\
+(?)\end{array}$ & $\begin{array}{c}0 \\
0 \\
16,00\end{array}$ & $\begin{array}{c}0 \\
0 \\
28,00\end{array}$ & $\begin{array}{l}0 \\
0 \\
7,22 \\
+(?)\end{array}$ & $\begin{array}{l}4,92 \\
0 \div-\infty \\
11,30 \\
+(?)\end{array}$ & $\begin{array}{l}0 \\
0 \\
8,20\end{array}$ & $\begin{array}{l}0 \\
0 \\
17,40\end{array}$ & $\begin{array}{l}0 \\
0 \\
22,23 \\
(7,4-48,4) \\
0\end{array}$ & $\begin{array}{l}0 \\
+(?) \\
38,44 \\
(17,4-72,9) \\
0\end{array}$ \\
\hline
\end{tabular}

Tab. 5. Qualitativer Nachweis der 8-Hydroxychinaldinsäure im Urin von 2 Phenylketonurie-Patienten. A: unruhiger Tag. Schreiattacken, Wutausbrüche usw., B: ruhiger Tag, Verhaltensweise ist auṣgeglichen.

\begin{tabular}{llllllllll}
\hline & A & B & A & B & A & A & B & B & A \\
\hline Patient Nr. 7 & + & 0 & + & 0 & + & $+(?)$ & 0 & 0 & ++ \\
Patient Nr. 9 & + & + & + & 0 & + & + & 0 & 0 & + \\
\hline
\end{tabular}

Errègbarkeit die 8-Hydroxychinaldinsäure im Urin nachgewiesen werden, nicht dagegen an Tagen mit ausgeglichener Verhaltensweise.

\section{Nicotinsäu rederivate}

Die Untersuchung der Nicotinsäurederivate führte zu keinen auffälligen Befunden. Picolinsäure, Nicotinsäure$\mathrm{N}$-Oxid und $\mathrm{N}_{1}$-Methyl-2-pyridon-5-carbonsäure konnten 
in Übereinstimmung mit Kontrolluntersuchungen nicht nachgewiesen werden. Im Gegensatz zu mehreren Literaturangaben konnte Chinolinsäure ebenfalls nicht nachgeweisen werden (17). Bei Kontrolluntersuchungen zur Bestimmung des $\mathrm{N}_{\mathbf{1}}$-Methylnicotinsäureamids wuirde die auffallige Beobachtung gemacht, daß bei Personen mit hoher Basalausscheidung eine Abnahme nach Tryptophan-Belastung erfolgt (Gruppe I), während bei den Personen mit niedrigem Basalwert eine Erhöhung nach Belastung eintritt (Gruppe II). Die Ergebnisse bei den Phenylketonurie-Patienten können der Kontrollgruppe II zugeordnet werden. Die Ausscheidung von $\mathrm{N}_{1}$-Methyl2-pyridon-5-carboxamid liegt im unteren Normbereich. Nicotinsäure und ihr Amid sind nur sporadisch nachweisbar. Bemerkenswert ist die Tatsache, daß Nicotinsäureamid nach Tryptophan-Belastung in geringerer Menge als vor Belastung ausgeschieden wird. Dies wurde auch bei Kontrollen mitunter festgestellt (17). Im Falle des $\mathrm{N}_{1}$-Methyl-4-pyridon-5-carboxamids und des Nicotinsäureamid-N-Oxids waren die Substanzmengen zu gering, um eine eindeutige Identifizierung durch spektroskopische Analysen herbeizuführen (Tab. 4).

\section{Ausscheidung unbekannter Metabolite}

Bei der dünnschichtchromatographischen Untersuchung der einzelnen Fraktionen aus der Säulenchromatographie wurden zahlreiche Substanzen gefunden, die bislang in Normalurinen noch nicht nachgewiesen werden konnten. Auf Grund der Tatsache, daß diese Metabolite nach Tryptophan-Belastung vermehrt ausgeschieden werden bzw. überhaupt erst nach Belastung beobachtet werden können, wird ein Zusammenhang mit dem TryptophanStoffwechsel angenommen. In Tabelle 6 wird eine $\mathrm{Zu}$ sammenstellung dieser unbekannten Metabolite gegeben. Es ist möglich, diese Metabolite auf Grund ihres Erscheinens in den einzelnen Urinen der 10 Patienten entsprechend den Gruppen A und B zu ordnen. Auf Grund der dünnschichtchromatographischen Beurteilung kann die allgemeine Aussage gemacht werden, daß mit zunehmendem Alter der Patienten die Anzahl der ausgeschiedenen, nicht identifizierten Metabolite zunimmt.

\section{Metabolit U1}

Im folgenden wird kurz über den neuen Metaboliten U1 berichtet, dessen chemische Struktur nicht völlig geklärt werden konnte. Als stabiles Bruchstück wurde o-Aminoacetophenon erkannt. In Kontrollurinen kann U1 nicht nachgewiesen werden. Bisher konnte dieser Metabolit nur bei den 3 Patienten der Gruppe B und bei dem Patienten Nr. 6 aus Gruppe A identifiziert werden. Die ausgeschiedenen Mengen sind im Basalurin sehr gering, nach Tryptophan-Belastung erfolgt jedoch eine ștarke Erhöhung. Patientin Nr. 9 ist durch die höchste Aus-。 scheidungsrate von U1 gekennzeichnet.

\section{Isolierung von $U 1$}

Nach Tryptophanbelastung werden $500 \mathrm{ml}$ Urin präparativ säulenchromatographisch auf Amberlite IR/120 AS aufgearbeitet. Die Elution erfolgt mit $0,05 \mathrm{~mol} / 1$ wäßrigem Pyridin/ Ameisensäure-Puffer vom pH 2,60 und 5,60. Die Fraktionen werden gefriergetrocknet und auf Cellulose dünnschichtchromatographiert (Laufmittel n-Butanol/Eisessig/Wasser, $40 \mathrm{ml}+$ $10 \mathrm{ml}+50 \mathrm{ml}$ ). U1 stellt nur eine Komponente aus einem Gemisch von mindestens 6 Substanzen dar, die alle mit van Urk's Reagenz gelb, orange und rot angefärbt werden können. Bei Anregung mit UV-Licht von $360 \mathrm{~nm}$ fluoreszieren sie türkis, blau und grün. U1 wird von der Dünnschicht präparativ isoliert. Die weitere Reinigung erfolgt auf Kieselgel mit den Laufmitteln Äthanol/Wasser ( $95 \mathrm{ml}+5 \mathrm{ml}) R_{F}$-Wert von U1 0,98

Athanol/Hexan $(10 \mathrm{ml}+10 \mathrm{ml}) \cdot \mathrm{R}_{\mathrm{F}}$-Wert von $\mathrm{U} 10,60$ Äthanol/Chloroform $(70 \mathrm{ml}+30 \mathrm{ml}) R_{F}$-Wert von $U 10,71$

Die Elution von der Dünnschicht erfolgt jeweils mit $n$-Butanol/ Äthanol $(10 \mathrm{ml}+10 \mathrm{ml})$. Nach dieser Reinigung zeigte Metabolit U1 dünnschichtchromatographisch nur einen mit van Urk's anfärbbaren Fleck. Die Lösung von U1 in Äthanol war hellgelb gefärbt und hatte einen leicht süßlichen, aminartigen Geruch.

Die gaschromatographische Untersuchung des isolierten, nicht derivatisierten U1 auf Gaschrom $Q+2 \% O V-17$ ergab einen reproduzierbaren Peak. Als Begleitsubstanzen konnten in geringen Mengen 2 Substanzen festgestellt werden, die massenspektroskopisch als Phthalsäuredibutylester und Phthalsäurediisooctylester identifiziert wurden (diese Produkte stammen nicht aus dem Urin). Bei Verwendung von Plastikflaschen zum Aufbewahren des Urins können sich die als Weichmacher verwendeten Ester herauslösen (19)). U 1 wurde nunmehr präparativ gaschromatographisch gereinigt.

Das UV-Spektrum (Abb. 1) mit den Absorptionsbanden bei 227, 260, 310 und $365 \mathrm{~nm}$ deutet auf einen Aromaten mit einer Amino- oder Hydroxylgruppe. In saurem Milieu erfolgte keine hypsochrome Bandenverschiebung, d. h. die durch eine Aminogruppe verursachten basischen Eigenschaften müssen sehr gering sein, wie z. B. auch aus der schwachen Adsorption an dem stark sauren Kationenaustauscher Amberlite abgeleitet werden kann.

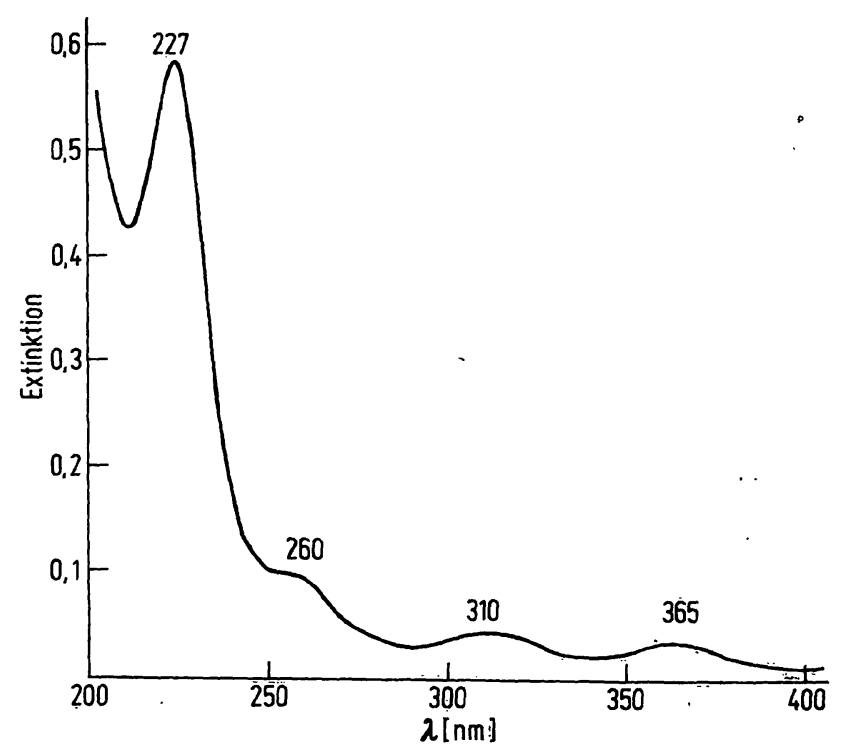

Abb. 1. UV-Absorptionsspektrum von Metabolit U 1, aufgenommen in Äthanol mit dem Cary 15. 


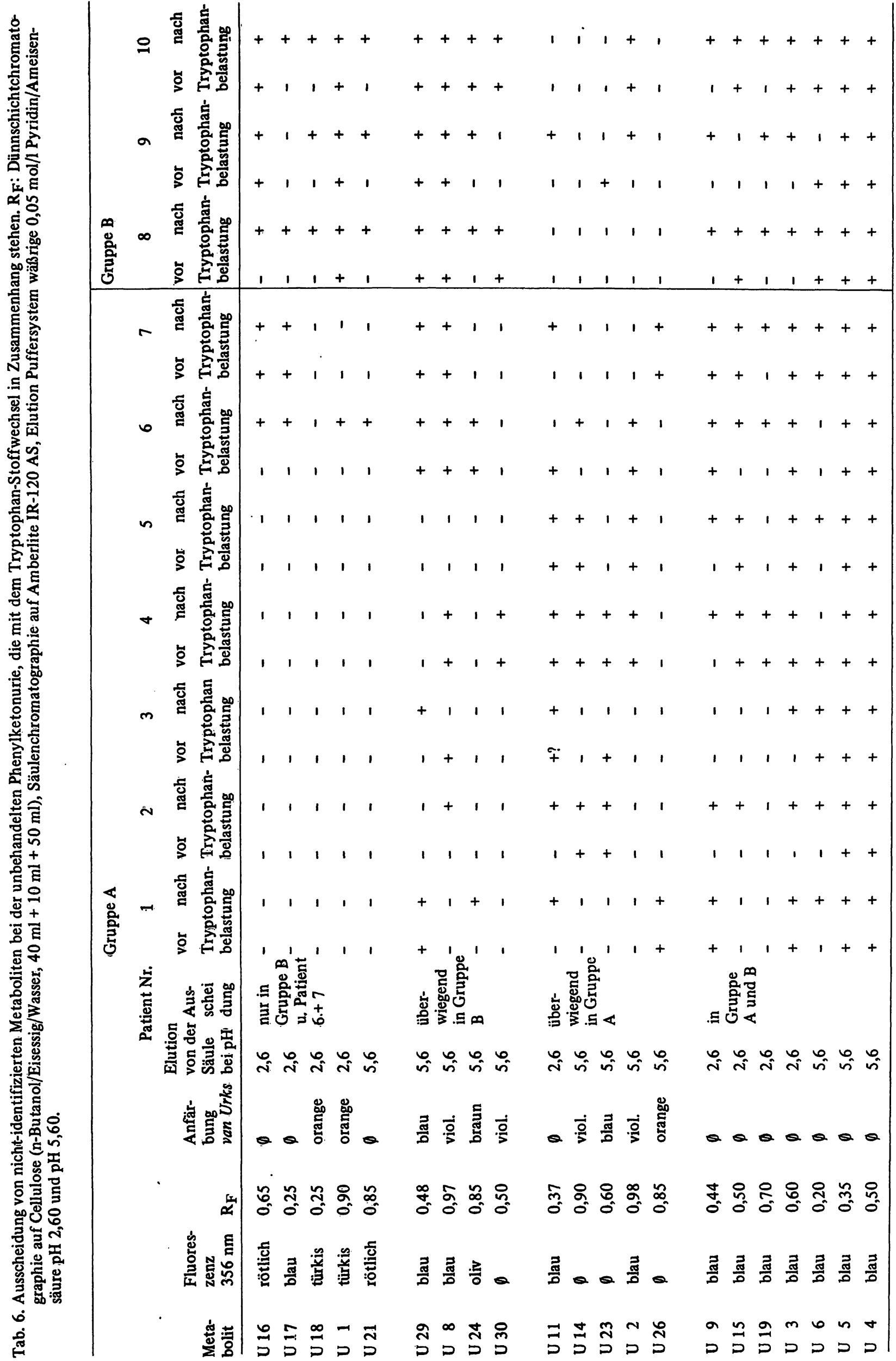


Aus dem Massenspektrum (Kombination Gaschromatographie und Massenspektrometrie) konnten weitere Hinweise über die Struktur der Substanz erhalten werden (Abb. 2).

Aus dem Parentpeak mit der MZ 135 wird sukzessiv $\mathrm{CH}_{3}, \mathrm{CO}$ und $\mathrm{HCN}$ abgespalten. Der Basispeak liegt bei MZ 120. Das ungrade Molgewicht und das Fragmentierungsschema $(20,21)$ führen zur Annahme eines substituierten Benzolringes mit einer Acetyl- und einer Aminogruppe, deren gegenseitige Stellung aus dem Massenspektrum aber nicht abzuleiten ist. Als Strukturvorschlag ergibt sich ein Aminoacetophenon. Das Massenspektrum von synthetischem 0 -Aminoacetophenon deckt sich mit dem Spektrum des gaschromatographisch isolierten Produktes mit Ausnahme eines Fragmentes mit der MZ 60, das im Vergleichsspektrum nicht auftritt.

Die infrarot-spektroskopischen Daten von U1 können jedoch nicht völlig mit der massenspektroskopisch ermittelten Struktur eines 0 -Aminoacetophenons in Ubereinstimmung gebracht werden (aufgenommen in $\mathrm{KBr}$ ):

\begin{tabular}{cl}
\hline Metabolit U1 & $\begin{array}{l}\text { authentisches } \\
o \text {-Aminoacetophenon }\end{array}$ \\
\hline$\nu\left(\mathrm{cm}^{-1}\right)$ & $\nu\left(\mathrm{cm}^{-1}\right)$ \\
3436 & 3460 \\
3000 & 3340 \\
$1640-1580$ & 1640 \\
& 1610 \\
& 1580 \\
$1480-1400$ & 1550 \\
& 1480 \\
1350 & 1450 \\
1240 & 1360 \\
1170 & 1240 \\
1020 & 1170 \\
930 & 1020 \\
750 & 955 \\
\hline
\end{tabular}

Dünschicht- und gaschromatographische Vergleiche zeigen weiterhin, daß die isolierte Substanz U1 nicht mit o-Aminoacetophenon und den anderen in Tabelle 7 aufgefuihrten biochemisch verwandten Vergleichssubstanzen identisch ist.

Es bestehen also Differenzen zwischen der massenspektroskopisch eindeutig ermittelten Struktur eines 0 -Aminoacetophenons und den dünnschicht- und gaschromatographischen Ergebnissen. Andererseits làssen die UVund IR-spektroskopischen Daten die Grundstruktur eines Aminoacetophenons erkennen. Es ist möglich, daß im Separator des Massenspektrometers eine Spaltung von $\mathrm{U} 1$ in 0 -Aminoacetophenon und ein unbekanntes Bruchstück eingetreten ist (19).

Diese Instabilität von Ü1 wird durch folgende Versuche deutlich:

Unter Umgehung der Säulenchromatographie wurde der Nativurin bei verschiedenen pH-Werten mit Äther extrahiert. Nach alkalischer Extraktion konnte weder U1

Tab. 7. Dünnschicht-chromatographischer Vergleich von $U 1$ auf Kieselgel $F_{254}$ mit biochemisch verwandten Substanzen. System 1: Äthanol/Hexan $10 \mathrm{ml}+10 \mathrm{ml}$, System 2: Äthanol/Chloroform $70 \mathrm{ml}+30 \mathrm{ml}$

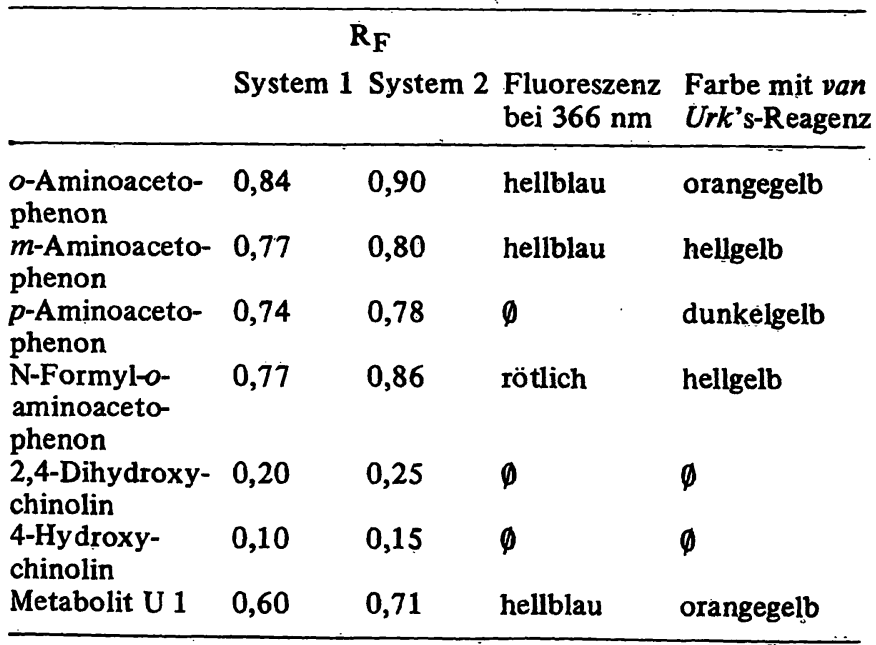

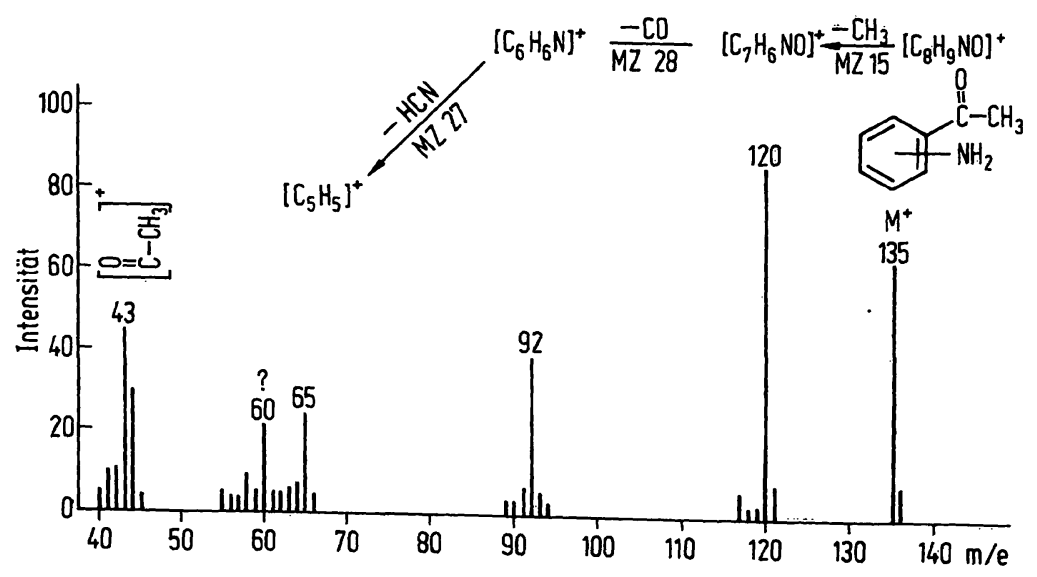
Abb. 2. Massenspektrum von Metabolit U 1, Kombination Gas-Chromatographie/Massenspektrometrie, aufgenommen mit dem
LKB 9000 . 
noch freies 0 -Aminoacetophenon durch Dünnschichtund Gaschromatographie nachgewiesen werden. Säuert man den Urin auf pH 1 an, so entsteht freies $O$-Aminoacetophenon, das sich im alkalischen Milieu mit Ä ther extrahieren läßt. U1 konnte nicht nachgewiesen werden.

Die geschilderten Versuche führen zu dem Schluß, daß freies $O$-Aminoacetophenon im Urin nicht vorhanden ist. Es wird wahrscheinlich in einer biogenetischen Vorstufe ausgeschieden, die infolge ihrer thermischen Instabilität und ihrer Säureempfindlichkeit sehr leicht in o-Aminoacetophenon und ein unbekanntes Bruchstück gespalten wird.

\section{Diskussion}

Die bisher in der Literatur veröffentlichten Ergebnisse über den oxydativen Tryptophan-Stoffwechsel bei Phenylketonurie sind nicht einheitlich. Anderson et al (7) beobachteten bei 4 von 6 untersuchten Phenylketonurie-Fällen (Alter 5-13 Jahre, Phenyalanin 220$380 \mathrm{mg} / 1$ Serum) eine gering verminderte Gesamtausscheidung der oxydativen Metabolite nach TryptophanBelastung, während unter Basalbedingungen die Werte im oberen Normbereich lagen. Bei 2 Fällen waren Abweichungen von der Norm nicht festzustellen. Analoge Untersuchungen von Vassella et al (8) ergaben eine gering reduzierte Ausscheidung der meisten Metabolite aus dem Kynurenin-Abbau. Tada \& Bessman (9) geben eine Verminderung der Ausscheidung von Kynuren- und Xanthurensäure und von' $\mathrm{N}_{\mathbf{1}}$-Methylnicotinsäureamid von 14-36\% an. Careddu et al (10) fanden in ihren Untersuchungen keine Abweichungen von der Norm. Heeley's Ergebnisse (11) lassen dagegen bei unbehandelten Phenylketonurie-Säuglingen eine Tendenz zur erhöhten Ausscheidung von Kynurenin, 3-Hydroxykynurenin und von Xanthürensäure erkennen.

Will man die eigenen, quantitativen Ergebnisse über die ausgeschiedenen Tryptophan-Metabolite mit den Werten aus der Literatur vergleichen (7-11), so wird dort allgemein eine absolut größere Ausscheidungsrate festgestellt. Neben physiologischen Schwankungen ist nach unserer Meinung die angewandte Methode ausschlaggebend: Die quantitative Auswertung erfolgt bei unseren Untersuchungen erst dann, wenn nach säulenchromatographischer Auftrennung des Urins die dünnschicht- und gaschromatographische, eindeutige Identifizierung eines Metaboliten feststeht. Die Ergebnisse von Schievelbein et al (22), die 3-Hydroxyanthranilsäure und 3-Hydroxykynurenin enzymatisch bestimmten, sind in sehr guter Übereinstimmung mit unseren Normalwerten.

Unsere Ergebnisse bei der Untersuchung des Phenylketonurie-Kollektivs führten zu einer Einteilung der Patienten in 2 Gruppen A und B, deren Tryptophan-Stoffwechsel offensichtlich in verschiedener Weise beeinflußt wird. Diese Einteilung korreliert weitgehend mit einer
Gruppierung nach den Serumwerten des Phenylalanins. Bei den Patienten der Gruppe A liegen die PhenylalaninKonzentrationen zwischen 150-250 mg/1 Serum, bei Gruppe B dagegen zwischen $60-120 \mathrm{mg} / 1$. Das Alter der Patienten scheint ein 2. Parameter zu sein, denn alle Patienten der Gruppe B sind älter (20-35 Jahre).

In Anbetracht von neuen Erkenntnissen über die verschiedenen Formen der Phenylketonurie erhebt sich nun die Frage, ob bei den Patienten der Gruppe B eine Phenylketonurie im klassischen Sinne, eine atypische Form oder eine Hyperphenylalaninämie vorliegt. Zur Diskussion vergleiche 1.c. (23).

Die quantitative Bestimmung der $O$-Hydroxyphenylessigsäure ist als diagnostisches Kriterium zur Unterscheidung einer Phenylketonurie von einer Hyperphenylalaninämie vorgeschlagen worden (24-26). Zur diagnostischen Abklärung wurde bei der Patientin Nr. 9 , die durch ihr qualitatives und quantitatives Ausscheidungsmuster der Metabolite im Urin besonders aufgefallen war, im Nüchternzustand eine orale PhenylalaninBelastung $(0,1 \mathrm{~g} / \mathrm{kg}$ Körpergewicht) durchgeführt. Der Ausgangswert für Phenylalanin betrug $93 \mathrm{mg} / 1$ Serum, das Maximum von $260 \mathrm{mg} / \mathrm{l}$ wurde nach 50 Minuten erreicht und veränderte sich bis zur 4 . Stunde nicht. Nach 5 Stunden erfolgte ein Abfall auf $220 \mathrm{mg} / \mathrm{l}$, nach 6 Stunden auf 190, nach 8 Stunden auf 160 und nach 16 Stunden auf $110 \mathrm{mg} / 1$. Der Ausgangswert wurde erst nach etwa 34 Stunden wieder erreicht. Das zu denselben Zeitpunkten bestimmte Tyrosin stieg nach 6 Stunden auf einen Maximalwert, der um $30 \%$ höher lag als der Ausgangswert. Vor der Belastung mit Phenylalanin wurden die Phenolsäuren im Urin gaschromatographisch bestimmt:
$o$-Hydroxyphenylessigsäure
Phenylmilchsäure
Phenylbrenztraubensäure
freie Phenylessigsäure
konjugierte Phenylessigsäure
$0,050 \mathrm{~g} / \mathrm{g}$ Creatinin $0,150 \mathrm{~g} / \mathrm{g}$ Creatinin $0,230 \mathrm{~g} / \mathrm{g}$ Creatinin $0,080 \mathrm{~g} / \mathrm{g}$ Creatinin $0,160 \mathrm{~g} / \mathrm{g}$ Creatinin

Diese Werte liegen im unteren Bereich der Werte, die von Vavich et al (27) mit derselben gaschromatographischen Methode bei unbehandelten Phenylketonurikern ermittelt worden waren.

Unter der oralen Phenylalanin-Belastung war in den einzelnen Urinportionen ein deutlicher Anstieg von Phenylbrenztraubensäure und Phenylmilchsäure festzustellen. Der Anstieg der $O$-Hydroxyphenylessigsäure setzte später ein. Innerhalb von 6 Stunden nach Belastung wurden $33 \mathrm{mg} o$-Hydroxyphenylessigsäure im Urin ausgeschieden. Mit Ausnahme der konjugierten Phenylessigsäure wurde bei den anderen 4 Metaboliten ein Konzentrationsabfall festgestellt, der parallel zum. Abfall des Phenylalanins im Serum verlief.

Diese ergänzenden Untersuchungen zeigen, daß die Phenylalanin-Toleranzkurve nicht den typischen Verlauf 
wie bei der klassischen Phenylketonurie aufweist, sondern durch einen konstanten Abfall innerhalb der ersten 24 Stunden gekennzeichnet ist, wie er z. B. von Blaskovics \& Shaw (28) bei Varianten der Hyperphenylalaninämie berichtet worden ist.

Es wird heute die Ansicht vertreten (29), daß eine schwere Hirnschädigung nur bei der klassischen Phenylketonurie anzutreffen ist, nicht dagegen bei den Varianten. Es muß durchaus in Erwägung gezogen werden, daß die Hirnschädigung bei den 3 Patienten der Gruppe $B$ eine andere Ursache als bei der klassischen Phenylketonurie haben könnte. Solange keine enzymatischen Untersuchungsergebnisse über die Aktivität des Phenylalanin-Hydroxylasesystems vorliegen, muß eine letzte diagnostische Entscheidung noch aufgeschoben werden.

Bei Gruppe A mit ihren höheren Phenylalanin-Werten (150-250 mg/1 Serum) wird eine Verminderung der Ausscheidung von oxydativen Abbauprodukten des Tryptophans beobachtet, die aber erst nach TryptophanBelastung signifikant sichtbar wird. Bei den Patienten der Gruppe B steigt die Ausscheidung der Metabolite sowohl unter Basal- wie Belastungsbedingungen über die Norm an. Nach Trỳptophan-Belastung ist die Ausscheidung um das Vierfache der Norm erhöht.

Eine detaillierte Analyse des Indol-Stoffwechsels bei denselben Patienten ergab ebenfalls signifikante Unterschiede, die zu einer analogen Einteilung in 2 Gruppen $A$ und $B$ führten (13).

In welcher Weise nun die Serumkonzentration des Phenylalanins die Ausscheidung der Tryptophan-Metabolite beeinflußt, ist noch ungeklärt. Als Erklärung für den verminderten Tryptophan-Stoffwechsel bei der Phenylketonurie werden in der Literatur folgende Beobachtungen angeführt:

1. Die Tryptophan-Pyrrolase wird durch die vermehrt gebildeten Stoffwechselprodukte aus dem Metabolismus des Phenylalanins $(9,30)$ und der Indolabkömmlinge (31) partiell inhibiert. Hemmende Effekte haben aber auch Metabolite aus dem oxydativen Abbau des Tryptophans, das NAD selbst und seine Vorstufen (32).

2. Die intestinale Resorption des Tryptophans ist gestört (33). Die Serumwerte für Tryptophan liegen bei unbehandelten Phenylketonurikern um die Hälfte niedriger als bei Kontrollen $(5,4$ gegenüber $11,3 \mathrm{mg} / \mathrm{l})$. Dementsprechend liegt auch das 1-2 Stunden nach Tryptophan-Belastung im Blut erreichte Maximum der Konzentration um $50 \%$ niedriger. Tryptophan wird nach Belastung in großen Mengen im Stuhl nachgewiesen, bei Kontrollen ist der Nachweis negativ (34). Es gibt Hinweise, daß Phenylalanin bei der intestinalen Resorption von Tryptophan und Tyrosin eine bedeutende Rolle spielt (35-38).
Eine Erklärung für den erhöhten Tryptophan-Stoffwechsel bei der Gruppe B ist z. Zt. noch nicht möglich. Eine Tracer-Studie mit am Benzolring ${ }^{14} \mathrm{C}$-markiertem Tryptophan bei einem Patienten der Gruppe B ergab, daß die gesamte Resorption und der metabolische Umsatz des Tryptophans noch größer ist als aus den inaktiven Versuchen zu ersehen ist (39).

Die Beziehung zwischen Serum-Phenylaląnin und Tryptophan-Stoffwechsel konnte in einem Diätversuch bei einem Patienten aus Gruppe A aufgezeigt werden. Wird die Serumkonzentration des Phenylalanins gesenkt, so verändert sich die Basal- und Belastungsausscheidung der Tryptophan-Metabolite und gleicht sich dem Ausscheidungsmuster der Gruppe B an (40).

Es ist schwer $\mathrm{zu}$ verstehen, warum der reduzierte Tryptophan-Stoffwechsel bei Gruppe A sich nicht Normwerten nähert - wie doch zu erwarten wäre -, wenn der Phenylalanin-Spiegel herabgesetzt wird. Es wird aber vielmehr eine exzessive Umsatzsteigerung des Tryptophan-Stoffwechsels festgestellt. Man muß also annehmen, daß die Wechselbeziehungen zwischen PhenylalaninSpiegel und Tryptophan-Stoffwechsel wesentlich komplizierter sind als die einfache Vorstellung, daß erhöhte Phenylalanin-Konzentrationen die intestinale Resorption des Tryptophans hemmen. Dadurch kann auch nicht der stark erhöhte Umsatz des Kynurenin-Abbauweges erklärt werden. Es müssen andere Faktoren vorhanden sein, die zu einer Induzierung der TryptophanPyrrolase oder pyrrolase-ähnlichen Enzymen (41) führen.

Besondere Erwähnung verdienen die zahlreichen unbekannten Metabolite, die in beiden Gruppen entdeckt wurden und die teilweise für eine Gruppe sogar charakteristisch sind. Bei der erwähnten Tracer-Studie (39) wurden über 50 unbekannte radioaktive TryptophanMetabolite dünnschichtchromatographisch nachgewiesen. Bei Kontrolluntersuchungen waren diese unbekannten Metabolite nicht nachweisbar. Über solche Befunde ist in der Literatur bisher nicht berichtet worden.

Das für die Gruppe B so charakteristische o-Aminoacetophenon bzw. seine biogenetische Vorstufe ist ein Beispiel für die Notwendigkeit der Erforschung des pathophysiologischen Tryptophan-Stoffwechsels. Die Frage nach der biogenetischen Ableitung wirft besondere Probleme auf. Als Vorläufer dieses Metaboliten kann die $o$-Aminobenzoylessigsäure bzw. ihre N-Formylverbindung angesehen werden (Abb. 3).

Ihre Entstehung kann wie folgt diskutiert werden:

1. Bildung aus N-Formylkynurenin, dem ersten Spaltungsprodukt aus der Pyrrolase-Reaktion. Nach Abspaltung der Formylgruppe bildet sich durch eine Pyridoxin-abhängige Transaminase die 0 -Aminobenzoylbrenztraubensäure, die sich spontan unter Ringschlußbildung zu Kynurensäure stabilisiert. Ist jedoch eine Ringbildung nicht möglich, indem $\mathbf{z}$. B. die 


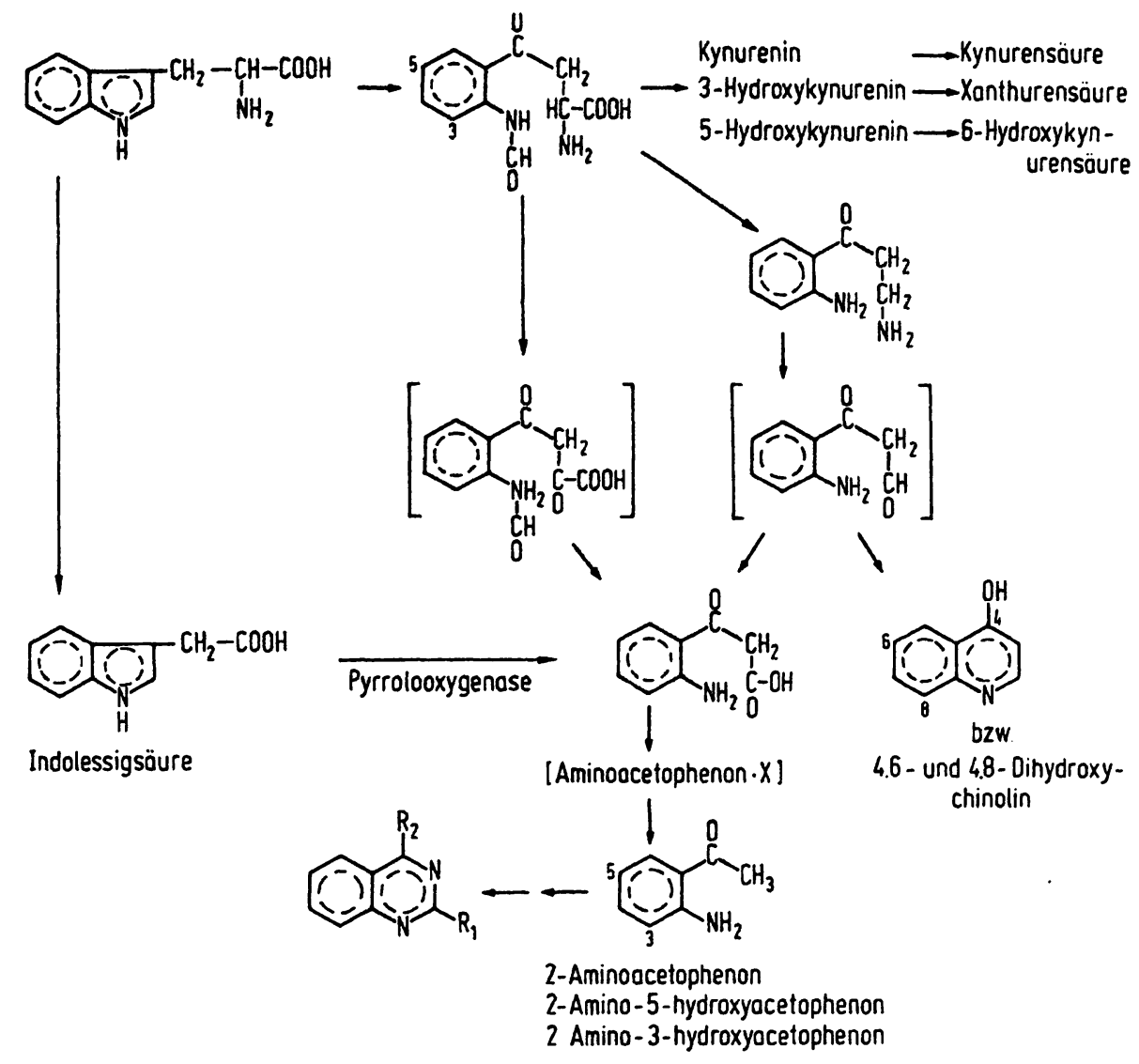

Abb. 3. Biogenetische Möglichkeiten der Entstehung von o-Aminoacetophenon.

Aminogruppe formyliert bleibt, so wird die Diketosäure infolge ihrer Instabilität zur analogen Benzoylessigsäure decarboxylieren. Von ihr ist bekannt, daß sie im sauren, neutralen und alkalischen Milieu zu o-Aminoacetophenon bzw. ihrem N-Formylderivat decarboxyliert (42).

2. Eine weitere Möglichkeit zur Bildung der 0 -Aminobenzoylessigsäure ist die Spaltung der Indol-3-essigsäure in einer pyrrolase-ähnlichen Reaktion. Von Interesse ist die wenig beachtete Arbeit von Frydman et al (43), die in Weizenkeimlingen, in der Leber und im Gehirn der Ratte ein Enzym (Pyrrolooxygenase) nachweisen konnten, das Skatol und Indol-3-essigsäure zu dem $\mathrm{N}$-Formylderivat des $O$-Aminoacetophenons aufsprengt.

Die freie 0 -Aminobenzoylessigsäure kann aus dem Urin nicht isoliert werden, da sie bereits in sehr schwach saurem Milieu in 4-Hydroxychinolon-2 übergeht (42). Versuche, dieses Ringschlußprodukt im Urin von Phenylketonurie-Patienten nachzuweisen, verliefen negativ. Es muß als gesichert gelten, daß im Urin der Phenylketonurie-Patienten der Gruppe B freies $O$-Aminoacetophenon nicht vorhanden ist, sondern eine instabile Vorstufe, aus der leicht $o$-Aminoacetophenon als stabiles Abspaltungsprodukt entsteht.
In der Literatur ist über eine Ausscheidung von 0 -Aminoacetophenon nur sehr wenig bekannt. Die Substanz wurde im Urin von Cushing- und Leukämieerkrankten $(44,45)$, in Knochenmarkszellen und in der Milz von Ratten (46) nachgewiesen. Mangelnde experimentelle Angaben lassen die Möglichkeit offen, daß auch hier $o$ Aminoacetophenon ein Abspaltungsprodukt darstellt. Der bei Kulturen von Pseudomonas aeruginosa auftretende Geruchstoff konnte als $o$-Aminoacetophenon identifiziert und seine Biogenese aus ${ }^{14} \mathrm{C}$-Tryptophan sichergestellt werden $(47,48)$. Dieser Metabolit stellt das Ausgangsprodukt für. die Bildung von Chinazolinderivaten dar.

In menschlichen Normalurinen konnte $o$-Aminoacetophenon von uns bisher nicht nachgewiesen werden. Negative Ergebnisse erhielt auch Brown (49), der eine Nachweisempfindlichkeit von $10 \mu \mathrm{g} / 24$-h-Urin erreichte. Bei Verfutterung an Kaninchen erfolgt eine Metabolisierung zu Anthranilsäure und zum Glucuronid des o-Aminophenylmethylcarbinols (50).

Uber Hydroxyderivate des 0 -Aminoacetophenons ist in letzter Zeit mehrfach berichtet worden. Kido et al. konnten zeigen, daß 2-Amino-3-hydroxyacetophenon nach extrem hohen Dosen von Tryptophan (51) und nach Verfütterung von 0 -Aminoacetophenon (52) im 
Urin von Ratten ausgeschieden wird. Die bei der Bestimmung durchgefuihrte saure Hydrolyse läßt auch.hier die Möglichkeit einer Spaltung des nativen Produktes offen. Lebermikrosomen können die Hydroxylierung in 3-Stellung durchführen (52). Das O-Sulfatderivat ist bereits 1955 im Humanurin nachgewiesen worden (53). Die Bildung von 4.6- und 4.8-Dihydroxychinolin, die nach Injektion von Tryptophan bei Hennen beobachtet wurde $(54,55)$, ist von biogenetischem Interesse (vgl.

\section{Literatur}

1. Colombo, J. P., Vassella, F., Humbel, R. \& Rossi, E. (1967), Helv. Paediat. Acta 22, 243-251.

2. Sutherland, B. S., Berry, H. K. \& Shirkey, H. C. (1960), J. Pediat. 57, 521-529.

3. Allen, R. I. \& Gibson, R. M. (1961), Amer. J. Dis. Child. $102,145-152$.

4. Marbry, C. C. \& Podoll, E. (1963), J. Pediat. 63, 1038.

5. Bickel, H. \& Grüter, W. (1957), Z. Kinderheilk. 79, 509-521.

6. Armstrong, M. D. \& Robinson, K. S. (1954), Arch. Biochem. Biophys. 52, 287-288.

7. Anderson, J. A., Bruhl, H., Michaels, A. J. \& Doeden, D. (1967), Pediat. Res. 1, 372-385.

8. Vassella, F., Colombo, J. P., Humbel, R. \& Rossi, E. (1968), Helv. Paediat. Acta 23, 22-36.

9. Tada, K. \& Bessman, S. P. (1960), Paediatrica Japonica 3, 41-46.

10. Careddu, P., Apollonio, T., Giovanni, M. \& Tenconi, L. (1964), Helv. Paediat. Acta 19, 267-278.

11. Heeley, A. F. (1965), Clin. Sci. 29, 465-473.

12. Byrd, D. J., Kochen, W., Idzko, D. \& Knorr, E. (1974), J. Chromatogr. 94, 85-106.

13. Kochen, W. \& Byrd, D. J. (1974), Clin. Chim. Acta (in Vorb.)

14. Auerbach, V. H., DiGeorge, A. M. \& Carpenter, G. G. (1967), in Amino Acid Metabolism and Genetic Variation (Nyhan, W. L., Hrsg.), 11-68, McGraw-Hill Book Company, New York, Toronto, London, Sydney.

15. Marbry, C. C. (1971), in Phenylketonuria (Bickel, H., Hudson, F. P. \& Woolf, L. J., Hrsg.) 81, Georg Thieme Verlag Stuttgart.

16. Kochen, W. \& Hochberg, K. (1970), Z. Krebsforsch. 73, 251-264.

17. Byrd, D. J. \& Kochen, W. (1974), J. Chromatog. (in Vorb.).

18. Kochen, W. (1971), diese Z. 9, 155-163.

19. Pohl, G., Firma Merck Darmstadt, Privatmitt.

20. Budzikiewicz, H., Djerassi, C. \& Williams, D. H. (1967), in Mass Spectrometry of Organic Compounds, 163, HoldenDay, Inc., San Francisco-London-Cambridge-Amsterdam.

21. Burey, M. M. \& McLafferty, F. W. (1966), J. Amer. Chem. Soc. $88,529-536$.

22. Schievelbein, H., Vortrag: Bemerkungen zur Analytik von Tryptophan Metaboliten, in Konferenz Analytik und Pathophysiologie des Tryptophan Stoffwechsels, Klinik Höhenried der LVA, 27.-28. Sept. 1971.

23. Bickel, H. (1970), Neuropädiatrie 1, 379-382.

24. Berry, H. K. (1967), in Phenylketonuria and Allied Metabolic Diseases. Proceedings of a Conference held at Washington, D.C. April 6-8, 1966, 87-98, U.S. Department of Health, Education, and Welfare, Social and Rehabilitation Service.

25. Woolf, L. J. (1963), Adv. Clin. Chem. 6, 165.

26. Taniguchi, K. \& Armstrong, M. D. (1963), J. Biol. Chem. 238, 4091-4097.

27. Vavich, J. M. \& Howell, R. R. (1971), J. Lab. Clin. Med. $77,159-168$

28. Blaskovicz, M. E. \& Shaw, K. N. F. (1971), in Phenylketonuria (Bickel, H., Hudson, F. P. \& Woolf, L. J., Hrsg.), 98, Georg Thieme Verlag Stuttgart.

29. Berman, J. L., Cunningham, G. C., Day, R. W., Ford, R. \& Hsia, D. Y. Y. (1969), Amer. J. Dis. Child, 117, 54-65.
Abb. 3). Aus Rattenduinndarm wurde eine Enzymfraktion angereichert, die die Umwandlung von 5-Hydroxykynurenin in 4.6-Dihydroxychinolin katalysiert (56). Das als weiteres Reaktionsprodukt gefundene 2-Amino5-hydroxyacetophenon (57) veranlaßte Kido et al (57) zu der Vermutung, daß die Chinolinderivate über 3bzw. 5-Hydroxykynurenamin - unter Annahme des Benzoylacetaldehydderivates àls Zwischenstufe - entstehen.

30. Bessman, S. P. (1964), J. Pediat. 64, 828-838.

31. Frieden, E., Westmark, G. W. \& Schorr, J. M. (1961), Arch. Biochem. Biophys. 92, 176-182.

32. Wagner, C. (1964), Biochim. Biophys. Res. Comm. 17, 668-673.

33. Bessman, S. P. \& Tada, K. (1960), Metabol. 9, 377-386.

34. Yarbro, M. T. \& Anderson, J. A. (1966), J. Pediat. 68, 895-904.

35. Lin, E. C. \& Wilson; T. H. (1960), Amer. J. Physiol: 199, 127-130.

36. Spencer, R. P. \& Samiy, A. H. (1960), Amer. J. Physiol. 199, 1033-1036.

37. Spencer, R. P. \& Samiy, A. H. (1961), Amer. J. Physiol. 200, 501-504.

38. Scriver, C. R. (1967), in Phenylketonuria and Allied Metabolic Diseases. Proceedings of a Conference held at Washing ton, D.C. April 6-8, 1966 (Anderson, J. A. \& Swaiman, K. F., Hrsg.), U.S. Department of Health, Education, and Welfare, Social and Rehabilitation Service, Children's Bureau, 181-192.

39. Kochen, W. \& Byrd, D. J., in Vorb.

40. Byrd, D. J., Kochen, W. \& Schürrle, L. (1974), Pediat. Res. (in Vorb.).

41. Hayaishi, O., in First Intern. Meeting on Tryptophan Metabolism: Biochemistry, Pathology and Regulation, Padova, 2. -4. Mai 1974.

42. Schöpf, C., Koepke, G., Kowald, B., Schülde, F. \& Wunderlich, D. (1956), Chem. Ber. 89, 2877-2886.

43. Frydman, R. B., Tomaro, M. L. \& Frydman, B. (1971), FEBS Lett., 17, 273-276.

44. Shapiro, G. A., Chernov, G. A. \& Ivanova V. D. (1966), Vop. Med. Khim. 12, 189-192.

45. Ivanova, V. D. \& Raushenbakh, M. O. (1964), Probl. Gematol. Periliv. Krovi 9, 3-10.

46. Zharova, E. J., Kuzuetsova, L. E. \& Rauhenbakh, M. O. (1968), Tsitol. Genet. 2, 538.

47. Mann, S. (1966), Arch. Mikrobiol. 54, 184-190.

48. Mann, S. (1967), Arch. Mikrobiol. 56, 324-329.

49. Brown, R. R., University Hospitalis, Div. of Clinical Oncology, Madison, Wisconsin 53706, Privatmitt.

50. Inagaki, Y. (1933), Hoppe-Seyler's Z. Physiol. Chem. 214, 25.

51. Kaseda, H., Noguchi, T., Kido, R. \& Matsumura, Y. (1970), Experientia 26, 828-829.

52. Kaseda, H., Noguchi, T., Konishi, N. \& Kido, R. (1971), Experientia 27, 368-369.

53. Dalgliesh, C. E. (1955), Biochem. J. 61, 334-337.

54. Kido, R., Noguchi, T., Tsuji, T. \& Matsumura, Y. (1967), Biochim. Biophys. Acta 136, 131-135.

55. Kido, R., Noguchi, T. \& Matsumura, Y. (1967), Biochim Biophys. Acta 141, 270-275.

56. Naguchi, T., Kaseda, H., Kido, R. \& Matsumura, Y. (1970), J. Biochem. 67, 113-121.

57. Naguchi, T., Kaseda, H., Kido, R. \& Matsumura, Y. (1970), J. Biochem. 68, 245-247.

Dr. W. Kochen

Univ. Kinderklinik

Isotoperiabt.

69 Heidelberg

Im Neuenheimer Feld 